\title{
Rose's Prevention Paradox
}

Christopher Thompson

University of Groningen

(Forthcoming in the Journal of Applied Philosophy - please cite the published version)

\begin{abstract}
Geoffrey Rose's 'prevention paradox' occurs when a population-based preventative health measure that brings large benefits to the community - such as compulsory seatbelts, a 'fat tax', or mass immunisation - offers little to each participating individual. Although the prevention paradox is not obviously a paradox in the sense in which philosophers understand the term, it does raise important normative questions. In particular, should we implement population-based preventative health measures when the typical individual is not expected to gain from them? After canvassing other attempts to address the paradox, I argue that what is significant about the prevention paradox is that it involves intra-personal trade-offs; the costs and benefits of the choice to implement or not implement a preventative health measure fall on the same individuals. The intra-personal nature of these trade-offs has two implications. First, the solutions to the paradox proposed by other authors are deficient. Second, the policy choice to not implement some preventative health measures can be normatively justified.
\end{abstract}




\section{Introduction}

Consider a public health problem such as the number of deaths from coronary heart disease. ${ }^{1}$ Broadly speaking there are two strategies we might pursue for dealing with the problem. The first strategy is termed 'high-risk', and involves targeting those at greatest risk of the condition. For example, if we are concerned with the number of deaths from coronary heart disease we might focus on treating only those individuals with the highest serum cholesterol levels, and the treatment might involve prescribing statins. The second strategy is termed a 'population' or 'mass' strategy, and involves treating a much wider group of individuals, up to and including the entire population. For example, if we are concerned with the number of deaths from coronary heart disease we might introduce a tax on fatty foods. ${ }^{2}$

The population strategy is likely to save more lives than the high-risk strategy. Why is this so? The epidemiologist Geoffrey Rose claimed that it is a fundamental axiom or principle of preventative medicine that "A large number of people exposed to a low risk is likely to produce more cases than a small number of people exposed to a high risk." ${ }^{3}$ The expected number of lives saved under each strategy is simply the decrease in the chance of death, multiplied by the number of people affected. In our example of coronary heart disease, the high-risk strategy leads to a large drop in the likelihood of death, but it applies to a relatively small number of people. By contrast the population strategy generates a slight reduction in the likelihood of death, but it applies to a large number of people. 
However, we now face what Rose calls the 'prevention paradox':

“... a preventative measure that brings large benefits to the community offers little to each participating individual." 4

For example, suppose we were to introduce a fat tax to reduce deaths from coronary heart disease (an example of a population strategy), and evidence from epidemiological studies suggests the associated reduction in consumption of fatty foods would prevent 1 in 50 heart attacks. While the total number of lives saved by this policy may be significant, it means that 49 out of every 50 people at risk of a heart attack - those targeted by the policy - change their diets for a lifetime and see no gain. ${ }^{5}$ In addition, such a policy means that many others in the population not at risk of a heart attack also change their diets and see no benefit (setting aside coincidental benefits, such as an improved physique).

The prevention paradox, as described by Rose, is not obviously a paradox in the sense in which philosophers understand the term - that is, as a set of apparently true but jointly inconsistent propositions. And the question of what will or will not motivate individuals to participate in preventative health measures is, ultimately, an empirical matter. But the prevention paradox does seem to raise important normative questions, in particular in distributive justice as applied to health care.

In what follows I follow Stephen John's ${ }^{6}$ distinction between the 'absolute' and 'relative' versions of the problem. In the absolute version of the prevention paradox the targets of the population strategy do not see the treatment as being worth their 
while, they do not want to participate, and we face a choice between implementing the population strategy or not. ${ }^{7}$ In the relative version of the prevention paradox, the targets of the population strategy $d o$ see the population treatment as being worth their while, and are happy to participate. However, in the relative version, we face a choice between implementing the population strategy or implementing a different high-risk strategy (by stipulation, cost or other factors mean we cannot implement both). ${ }^{8}$ In this paper I focus on the absolute version of the prevention paradox, and the correct normative response to it: should we implement population-based preventative health measures when the typical individual is not expected to gain from them and would prefer not to be subjected to them? ${ }^{9}$ For reasons that will become clear, the normative approach I propose for the absolute version of the prevention paradox does not work for the relative version of the prevention paradox, since the normatively significant features of the absolute and relative versions of the paradox are quite different.

\section{Geoffrey Rose's and Stephen John's solutions}

The prevention paradox poses a dilemma. As Rose himself says: "It is a common irony of preventative medicine that many people must take precautions in order to prevent illness in only a few."10; "There can be a conflict here between the collective interest, which requires community-wide change, and that of many of the individuals concerned, who could well consider that their prospect of benefit was negligible." ${ }^{11}$ It seems clear that Rose himself thought that population strategies should be implemented, in spite of the fact that they are to the expected disadvantage of all concerned: "Potentially far more effective [than the strategy targeted at high-risk individuals], and ultimately the only acceptable answer, is the mass strategy, whose aim is to shift the whole population's distribution of the risk variable."12; "Finally, the 
conclusion will be that preventative medicine must embrace both [the high-risk and population strategies], but, of the two, power resides with the population strategy."13

The first attempt to address the prevention paradox from a philosophical (as opposed to medical) perspective, that I am aware of, comes from Stephen John. ${ }^{14}$ John does attempt to frame Rose's problem as a paradox. John argues that the paradoxical nature of the prevention paradox rests on a fallacy of equivocation: the notion of 'benefit' is used in two slightly different ways. The prevention paradox arises since the same policy simultaneously harms everyone and benefits some people. From the perspective of individuals, the population strategy does more harm than good, since the costs of the treatment (the decreased consumption of delicious, fatty foods) are greater than the benefits (the decreased chance of dying). From a group level perspective, the population strategy does more good than harm since the lives saved seem worth the sum of the inconvenience from changed diets. The claim that each individual is harmed by the policy rests on an interpretation of 'benefit' as ex ante expected utility. The claim that some individuals are benefited by the policy relies on an interpretation of the 'benefit' as the ex post outcomes. The resolution of the prevention paradox, then, rests on which notion of benefit is primary. And which notion of benefit is primary determines the correct normative analysis of the absolute version of the prevention paradox: should we implement the population-based preventative measures, or not?

Stephen John posits ex ante contractualism as one normative framework that policymakers could apply to the prevention paradox. According to contractualism, "An individual can reasonably reject a principle (or set of principles) if and only if she can 
give some reason against their adoption and propose an alternative (set of) principle(s), such that no-one else has a stronger objection against her proposal than she has against the original." $"$ According to John's ex ante version of contractualism, these complaints are to be assessed according to the ex ante prospects facing individuals, rather than the ex post outcomes of the policy choice. From the ex ante perspective, each individual subject to the population strategy has a complaint against implementing the policy, since it does them more expected harm than expected good. From the ex ante perspective, no one has a complaint against failing to implement the policy (any complaints against failing to implement the policy come from the ex post outcome perspective of those who will die). Ex ante contractualism is the preferred normative framework for two reasons. First, ex ante contractualism gives normative prescriptions that are in line with common intuitions; many individuals and policy makers share the intuition that the population strategy should not be implemented, and ex ante contractualism provides normative backing for this intuition. ${ }^{16}$ Second, ex ante contractualism can accommodate the complaints of those in the population group who are asked to make the sacrifice of changing their diet for the sake of others, and can do so without suggesting that somehow the aggregate disutility of all those who have to change their diets is comparable to, and outweighs, the loss of life.

\section{Intra-personal trade-offs}

Both Rose and John seem to have overlooked an important feature of the prevention paradox, which ought to inform the correct normative response: there is no (direct) causal link between one person changing their diet and another person's life being saved. ${ }^{17}$ Changing your diet reduces the risk of death for you; changing your diet does not reduce the risk of death for anyone else. Any variation in the probability of your 
death from heart disease, that arises from changing or not changing your diet, is independent of the probability of death from heart disease for all other individuals. As a consequence, the decision to comply with the population strategy is not really an altruistic act, since compliance does not benefit other individuals. Instead, the absolute version of the prevention paradox involves trade-offs between two different potential future versions of the same individual.

There is a further reason why the features of the population strategy involve intrapersonal comparisons. The outcomes of individuals are independent, conditional on any common causes including participation or non-participation in the population strategy. The ex post harms experienced by some individuals (the instances of heart disease) are not necessary for the ex post gains experienced by other individuals (the avoidance of heart disease). ${ }^{18}$ Moreover, it is not the case that one individual avoiding heart disease comes at the expense of another individual who suffers heart disease. It is not as if there are a finite number of instances of avoiding heart disease that individuals compete for; it is entirely possible (if extremely unlikely) for all individuals to avoid heart disease.

Given that the absolute version of the prevention paradox involves intra-personal tradeoffs, how does this affect the correct normative response? Michael Otsuka and Alex Voorhoeve ${ }^{19}$ cite survey evidence that individuals are indifferent to the distribution of costs and benefits when it comes to intra-personal trade-offs; individuals apply what appears to be a 'utilitarian' normative framework, they maximise expected utility. ${ }^{20}$ For example, people are indifferent between a treatment that would entirely cure their slight impairment, and treatment that would turn their 
very severe impairment into a somewhat less severe impairment, given a 50/50 antecedent risk of having either condition. As Otsuka and Voorhoeve point out, if you are a morally motivated stranger who has to decide which treatment to apply to some person, then it seems appropriate to respect the preferences of this person and act so as to maximise their expected utility. ${ }^{21}$

The permissibility of maximising expected utility in intra-personal trade-offs, but not inter-personal trade-offs, depends on the moral unity and separateness of persons. As Otsuka and Voorhoeve state, “.... a single person has a unity that renders it permissible to balance (expected) benefits and burdens against each other that might accrue to her. A group of people, by contrast, does not possess such unity. As a consequence, some forms of balancing benefits and burdens that are permitted when these accrue to a single person are impermissible in cases where these benefits and burdens accrue to different people." 22

In the standard examples of the absolute version of the prevention paradox, the individuals subject to the population-based preventative strategy are autonomous adults, capable of well-informed and rational preferences. Moreover, the standard examples involve matters of public health policy over which the individuals ought to have a say. If it is permissible to maximise expected utility in cases of intra-personal trade-offs, then a respect for the autonomy of those involved requires not implementing the preventative strategy.

Suppose we were to implement a fat tax as a population strategy aimed at reducing the incidence of heart disease. It is possible to implement this policy with certain 
exemptions; the default may be a blanket percentage tax applied to certain categories of food, but certain individuals could be excluded from the tax, either by having the tax removed from their bill at the till point, or by claiming the tax back as part of their annual tax return. If a given individual wanted to be exempt from the fat tax, then what grounds are there for refusing this? Their exemption might impact on their own future health (if they now buy and consume more unhealthy food, and consequently develop heart disease), but their exemption from the fat tax does not harm the health of anyone else. And it is not as if they are free-riding on anyone else's compliance with the fat-tax - they do not directly or obviously benefit if others change their diets. To refuse an individual's request to be exempt from a fat tax would entail a violation of that individual's autonomy. All those who would be subject to the fat tax would want such an exemption, since by stipulation no-one believes such a tax is in their ex ante interests. So implementing the population strategy in an autonomy-respecting manner means that no individual would be subject to the fat tax.

Not all policies for implementing the population strategy will allow for such exemptions. For example, suppose that the most effective population strategy for reducing the incidence of cardiovascular disease is to force people to take more exercise by changing the physical infrastructure of a city. So elevators will be removed to encourage people to take the stairs, and parking spaces will be removed to make way for cycle lanes. ${ }^{23}$ Here we ought to take on board the lesson from instances in which it is possible to implement preventative strategies in an autonomy-respecting manner. If, when given the opportunity to do so, all would opt out of the population strategy then ought not to force compliance. 
The population strategy represents a case of intra-personal (rather than inter-personal) trade-offs: changing your diet now means you reduce your risk of heart attack in the future; not changing your diet now means you run an increased risk of heart attack in the future. Therefore, contrary to what Rose suggests, the precautions of the many do not prevent illness in a few; there is no conflict between the collective and individual interests, since the costs and benefits of deciding to forego a preventative treatment arise in two potential futures of the same individual.

Furthermore, the normative framework advanced by John, ex-ante contractualism, seems to be an overly complicated response to the absolute version of the prevention paradox. Contractualism requires that we choose the policy that is most acceptable to the individual with the strongest complaints. With the absolute version of the prevention paradox, we have three sources of potential complaints: the ex ante complaints against implementing the population treatment from those who would rather accept the risk of heart disease and not pay a fat tax or change their diets, the ex post complaints against implementing the population treatment from those who pay a fat tax or change their diets but for whom this does not benefit, and the ex post complaints in favour of implementing the population treatment from those whose life might be saved by a fat tax and change in diet. Why ignore the last two - ex post sources of complaints? John ${ }^{24}$ argues against actual harm (ex post) contractualism on the grounds that it gives normative prescriptions contrary to the common moral intuition that the population strategy should not be implemented; according to ex post contractualism, the complaints of those who will die if we do not implement the population treatment are stronger than the complaints of those who are inconvenienced by the population treatment. According to ex post contractualism we 
ought to implement the population-based preventative strategy of introducing a fat $\operatorname{tax}^{25}$

But if we acknowledge that the absolute version of the prevention paradox involves intra-personal trade-offs, then we need not choose between the moral intuitions and the normative theory, and we need not rule out ex post claims and ex post (actual harm) contractualism by stipulation. Rather, because we are dealing with intrapersonal comparisons, it is the individual agents themselves that choose to privilege their ex ante prospects over their own ex post outcomes.

The absolute version of the prevention paradox involves intra-personal trade-offs, and as such it is permissible to maximise individuals' expected utility. In examples, such as a proposal to introduce a fat tax to encourage healthy eating and thereby avoid deaths from coronary heart disease, it is correct to refuse to implement the policy on the basis that the costs outweigh the benefits, even if this policy decision will lead to a loss of life, since the costs and benefits fall on different possible futures of the same individuals. In a sense, the fact that the absolute version of the prevention paradox involves purely intra-personal trade-offs means that it is not really an issue of distributive justice at all. The only normative principle we need to appeal to, to justify not interfering in a purely private matter, is a concern for personal autonomy.

\section{Resisting inter-personal comparisons}

The normative account I have provided for the absolute version of the prevention paradox depends crucially on the claim that only intra-personal comparisons are 
relevant in such cases. Let me now present and address a number of possible objections to this claim.

First, a policy of not implementing the population strategy is ex ante Pareto efficient, that is to say, not implementing the population strategy maximises the expected utility for every person, and it would be impossible to improve the situation for one individual without making at least one other individual worse-off. This fact seems to count in favour of not implementing the population strategy. However, the ex post costs and benefits of not implementing the population strategy fall on different individuals; from the ex post perspective there are clear winners and losers from the policy (those who did not change their diets and are still alive vs. those who die from heart disease). The fact that there are ex post winners and losers from the decision to implement or not implement the population strategy suggests that, contrary to my core claim in this paper, the absolute version of the prevention paradox does not only involve intra-personal trade-offs. There are three related arguments against ex ante Pareto reasoning that must be addressed. The first of these arguments comes from Michael Otsuka and Alex Voorhoeve, the second from Thomas Scanlon, and the third from Alex Voorhoeve and Marc Fleurbaey.

The permissibility of maximising expected utility in cases comprising intra-personal trade-offs was supported above by analysis from Michael Otsuka and Alex Voorhoeve. ${ }^{26}$ But Otuska and Voorhoeve explicitly reject the application of this analysis to cases involving ex post inequality. They argue that focusing exclusively on the ex ante prospects of individuals, and the prudential argument ${ }^{27}$ for maximising each individual's expected utility, ignores the claims of individuals who end up ex 
post badly off and worse off than others due to bad brute luck. Otsuka and Voorhoeve note that one way ${ }^{28}$ of accounting for concerns with ex post inequality is that "...one must justify any claim on resources in light of the comparative strength of the claims of others." (p.183) The claims of the worst-off in a possible world in which we do not implement a fat tax (those who die from heart disease) are stronger than the claims of the worst-off in a possible world in which we do implement a fat tax (those who are frustrated by a fat tax). How, then, can we justify the policy of not implementing the fat tax to those individuals who will die from heart disease?

There is reason to think that the ex post inequality in absolute version of the prevention paradox might be justifiable to those who end up worst-off. If someone ends up ex post in a worse position than others, then this is the direct result of an attempt to benefit that individual by maximising their expected utility. As Fleurbaey and Voorhoeve ${ }^{29}$ note, "On the distributive view [of equal chances], a given outcome inequality among people with equally strong claims to a benefit is less unfair when each person has a chance to end up better off than when the worse off have no such chance, because in receiving this chance, each person receives an equal share of something of expected value." (p.123) Depending on how much weight we give to the ex post inequalities as opposed to the ex ante chances “...the fact that the equal chances offered by [an ex ante Pareto improving policy] mitigate the associated outcome-unfairness may tip the balance in its favor." (p.125) So now we need a reason to give weight to the ex ante chances rather than the ex post inequalities. In the absolute version of the prevention paradox there is such a reason for giving extra weight to the prudential concerns, namely a concern for individuals' autonomy. ${ }^{30}$ The individuals involved in the absolute version of the prevention paradox themselves 
weigh the ex ante prospects more highly than the ex post outcomes, and so we ought to respect this evaluation. ${ }^{31}$ And given that all individuals value their ex ante prospects over their ex post outcomes, it is not clear that any ex post inequalities that arise from maximising their expected utility give them any grounds for complaints.

Thomas Scanlon ${ }^{32}$ presents an argument against ex ante Pareto reasoning as part of a defence of contractualism. Scanlon argues that what is reasonable for an individual to accept is not the same thing as what is rational for an individual to accept. For Scanlon, an individual is bound to accept a principle if this individual judges that they cannot reasonably reject the principle, no matter what position they occupy in society. It may well be the case that every individual would rationally choose a principle of maximising expected utility behind a veil of ignorance, that is to say, if you did not know what position in society you occupied and assumed you had equal chance of filling any of these positions. The reason the ex ante rationality does not amount to reasonableness is that - ex post - there may well be some losers. If the position of these losers were significantly bad, they would have complaint against the policy. Applied to the prevention paradox, Scanlon's argument suggests that we should implement the preventative strategy in spite of protests. It may well be the case that perfectly rational people would not want to have their diets changed to reduce their risk of death from heart disease. However, the individuals who will go on to die from heart disease can reasonably reject the policy of refusing to implement the preventative strategy, given how bad their situation is.

Frances Kamm provides the best response to Scanlon's argument. As Kamm notes, “...even Scanlon can accept oftentimes an individual's actual (rather than 
hypothetical) choice to take a risk of falling into a disfavored position does undermine his complaint if he loses; such a choice can be a substitute for considering his perspective simply as a person in a disfavored position. Scanlon would have to explain either why hypothetical choice is different or in which circumstances risks are acceptable and in which not. ${ }^{, 33}$ Kamm notes that individuals often accept a small risk of death for the sake of a small gain. She cites Allan Gibbard's example of risking death in a car accident in order to purchase a chocolate bar; such a person would have no complaint if they were to die in a car accident. The question, then, is what such general willingness to take small risks means for hypothetical choices.

By stipulation, the agents involved in the prevention paradox cases prefer to not implement the policy since not implementing the policy maximises their expected utility. Given a choice, the individuals would be willing to take the risk and would not want the population strategy implemented. Policy makers can justify not implementing the population-based preventative health strategies since, not only is it in the prudential interests of the individual agents themselves, it is relevantly similar to the small risks they take every day, and is precisely what the individuals would have chosen for themselves of they were given the opportunity to choose. This prudential justification provides a response to any complaint presented by an agent who ends up as an ex post loser.

Marc Fleurbaey and Alex Voorhoeve ${ }^{34}$ provide a different but related argument against implementing policies on the basis of the policies' ex ante Pareto efficiency. They argue that choosing a policy based on ex ante Pareto efficiency conflicts with a requirement of rationality, namely, that if you can infer that you would invariably 
regard an alternative as best, given full information, then you should choose this alternative. With the prevention paradox, we know that there will be some people who will be harmed as a result of the decision to not implement the population strategy there will be avoidable deaths from heart disease. Although we don't know who these individuals are ex ante, we would know exactly who these individuals are with the full information provided by the ex post perspective. Given this full information given knowledge of precisely who will die if we fail to implement the population strategy - a failure to implement the strategy would seem wrong, since it could not be justified to those who will die as a result of the policy decision. If we know now that we would invariably choose to implement the population policy, given full information, then we ought to implement the policy.

Johann Frick ${ }^{35}$, in a response piece to Fleurbaey and Voorhoeve, argues that uncertainty - ex ante ignorance as to who will be the ex post winners and losers - can affect the normative ranking of policy alternatives, and so what you should choose in conditions of uncertainty is different to what you should choose under conditions of certainty. Ex ante it is impossible to know who will win and who will lose from a decision to implement or not implement the population strategy; what decision makers would decide, conditional on knowledge of who the ex post losers are is beside the point, since the antecedent of this conditional is never satisfied. Moreover, the individuals who would be subject to a decision to implement or not implement the population strategy would not want the decision maker to have the information as to who the ex post losers are, since this harms their ex ante interests by preventing them from maximising their expected utility. In combination these factors may well make a decision to not implement the population strategy justifiable to the ex post losers. 
Let's put to one side the concerns with ex ante Pareto reasoning and consider a second reason why inter-personal comparisons might be relevant in the absolute version of the prevention paradox. It was argued above that the intra-personal comparisons, constitutive of the absolute version of the prevention paradox, arise because of the independence of individuals. The change in one individual's risk of death given their (non)involvement in the preventative strategy is independent of all other individuals' risks of death, and the final outcomes of individuals are independent conditional on any common causal factors, including the choice over whether to implement the prevention strategy. There is, however, one important factor that does generate dependence between agents, namely the policy decision concerning whether or not to implement an exemption-free population strategy. It follows that one individual's willingness to support the implementation of a population strategy (perhaps by voting for such a strategy), can affect other's outcomes and so does involve at least some inter-personal comparisons. If you support the implementation of the population strategy, then someone else's life may be saved. But there is reason to resist this line of argument, and the associated inter-personal comparisons. Those who would benefit from the population strategy, and your support for it, do not want the strategy implemented. This is shown by the fact that they would opt out of the strategy if given the opportunity to do so. Respect for their autonomy requires not forcing the population strategy on them.

There is a third sense in which the prevention paradox is not purely a case of intrapersonal trade-offs. There is a weak sense in which the actions of those participating in the population strategy do benefit other people - the behavior of the high-risk 
people varies with the norm. ${ }^{36}$ If it becomes normal for the wider population to consume less fat in their diet, then the high-risk people may also change their diet slightly and receive the associated health benefits. As such, we might again argue that those in the population group should be willing to change their diet since doing so might help those who are at high-risk of death from coronary heart disease. But even if we can draw a causal connection between the actions of those in the population group and the effects on those at high-risk, the connection seems tenuous. It seems to ask too much that I change my diet for a lifetime on the basis that this might help those at highest risk by sending a social signal. This is particularly so if there are policy alternatives for reducing the risks of the high-risk individuals that do not require sacrifice on the part of low-risk individuals (prescribing statins to the highrisk individuals, for example). We also face a 'many hands problem'. A sizeable proportion of the wider population may need to change their diets so as to influence the behavior of high-risk individuals who vary with the norm. But there is no reason why I, in particular, need to be part of this social movement.

Finally, there may be a concern that the intra-personal trade-offs are a feature of the particular example of improving diets by placing a tax on fatty foods, rather than a feature of the absolute version of the prevention paradox per se. Suppose that we are still concerned with the number of deaths from heart disease, but that a leading cause of heart disease is viral infection (myocarditis). The particular policy proposal to reduce the incidence of heart disease is widespread vaccination. Although individuals may benefit themselves from being immunised, their decision to be immunised contributes to herd immunity and so is in part an altruistic act. This is particularly so as there will be some individuals who are not able to become immune themselves and 
so rely on the herd immunity. Here it seems that the prevention paradox is not purely a case of intra-personal trade-offs.

There are two possible responses to this line of argument. The first is to acknowledge the strength of the argument, and to consider cases in which one individual's participation in a population strategy does benefit another to be exceptions to the analysis I advance in this paper. ${ }^{37}$ An alternative response is to note that, by stipulation, the prevention paradox involves a case in which no individual wants to participate in the population strategy. Individuals have considered the disutility of participating in the population strategy, and risks of death given the choice not to participate. Individuals have come to the conclusion that their expected utility is maximised by the choice not to participate. If individuals are unwilling to take steps to reduce their own risks of heart disease by accepting immunisation (given that they are unaware they will rely on herd immunity), then they lack grounds for complaint if herd immunity is not available when they need it.

\section{The scope of the analysis}

The prevention paradox arises whenever a population-based preventive health measure is to individuals' ex ante disadvantage, but has ex post advantages at the population level. The absolute version of the prevention paradox occurs whenever there is a consensus among the individuals affected that they do not want to participate in the measure. Possible examples might include a fat tax, or the widespread prescription of statins aimed at reducing heart disease; compulsory cycle helmets, or compulsory seatbelts aimed at reducing road deaths; and a ban on smoking in private cars carrying no passengers, or an increase in tobacco tax (beyond 
what is required to recoup the additional public health costs generated by smokers) aimed at reducing lung cancer. All these examples have two features in common. First, an individual's involvement or non-involvement in the measure only affects their own health. Second, the individuals concerned are autonomous adults, capable of well-informed and rational preferences. Given that only intra-personal trade-offs are at stake, and given a respect for individual's autonomy, we ought not implement these population strategies.

Excluded from this analysis are cases where the actions of one individual do impact on another. So it may be justifiable to introduce a ban on smoking in public places, or a ban on cell phone use when driving, since smoking in public or driving while using a cell phone imposes risks on others.

Also excluded from this analysis are cases involving children, since they are incapable of autonomous decisions. For example, suppose widespread take-up of the HPV vaccine in girls would lead to a reduction in the incidence of cervical cancer in later life from $7 / 100,000$ to $5 / 100,000$, and would therefore reduce ex post inequality. Suppose for the sake of argument that being vaccinated is only marginally to an individual's ex ante disadvantage (although the disutility of cervical cancer is high, the probability is low, and being vaccinated is painful). In this example, the prudential argument against implementing the population strategy opposes the egalitarian argument in favour of implementation, but there are no concerns for autonomy to tip the balance in favour of the prudential argument. My own intuitions in this particular case, for what they are worth, are that here the egalitarian concerns are more important than the prudential concerns. The lesson may be that in cases such as this 
the details matter - if a policy is ex ante extremely disadvantageous this may trump a small gain in ex post equality; but if a policy is ex ante only slightly to an individual's disadvantage then this might be trumped by significant gains in ex post equality.

Now consider a case in which the government uses a public resource (e.g. state oil reserves) to subsidise statins for all (so that all are interested in taking them) even though everyone would rather have the cash in hand and no subsidised statins. ${ }^{38} \mathrm{I}$ presume that in this example the individuals affected are autonomous adults, but including a new alternative in an individual's option set, which the individual now prefers, does not violate their autonomy. There might, however, be an objection to this policy in the sense that a government is supposed to act as an agent of the individuals affected by its decisions. This seems like an example of a policy choice that the adults, as citizens in a democracy, have a right to make. If the voters don't want a public resource to be wasted on subsidising statins, then the government ought to respect that. In a modified case in which a drug company itself decides to crosssubsidise statins (so that all are interested in taking them), there is no objection at all: it is to the ex ante advantage of all, it reduces ex post inequalities, there are no autonomy violations, and it is irrelevant if the individuals would prefer different drugs to be subsidised (or would prefer cash in hand from the drug company), since the drug company is not acting as an agent of the individuals concerned and the individuals have no right to any subsidy at all from the drug company.

A final important caveat with the normative account I have provided for the prevention paradox is that even if surveys indicate that people are happy to be utilitarian with regard to intra-personal trade-offs, we still might want to give some 
extra weight to those possible future versions of people that are worst-off. We might argue that individuals are error-prone when it comes to calculating expected utility, for example, that people cannot properly comprehend the disutility from dying of a heart attack. As such, even if individuals are indifferent to the distribution of expected utility across different possible future versions of themselves, we might need to place extra weight on the possible future versions that are worst-off. Nevertheless, even if some weight is applied to the possible future versions of individuals that are worstoff, this weighting will not necessarily be total. In contrast to inter-personal cases, it seems perfectly permissible in intra-personal cases to compare and trade-off the inconvenience of changing your diet against saving your life, and this is permissible precisely because the costs and benefits arise in two possible futures of the same individual. $^{39}$

\section{Closing remarks}

In this paper I focus on the absolute version of the prevention paradox, where agents prefer that a population-wide preventative health strategy is not implemented, since the expected costs of the strategy outweigh the expected benefits. The core argument I make in this paper is that the correct normative response to this policy choice rests on recognising that instances of the absolute version of the prevention paradox involve intra-personal trade-offs. The costs and benefits of a decision to implement or not implement the population strategy arise in two possible futures of the same individual, and as such, it is permissible to maximise each individual's expected utility and not implement the policy. This normative prescription differs from that given by Rose himself, who suggested that population-wide preventative health strategies ought to be implemented. The normative prescription I advance for absolute version of the 
prevention paradox is, however, the same as the prescription given by John's ex ante contractualism, albeit for different reasons. In closing I argue that acknowledging the fact that intra-personal trade-offs are the key to the correct normative response to the absolute version of the prevention paradox, helps explain why ex ante contractualism does not work so well for the relative version of the prevention paradox.

Recall that in the relative version of the prevention paradox, the targets of the population strategy $d o$ see the population treatment as being worth their while, and are happy to participate. However, in the relative version, we face a choice between implementing the population strategy and implementing the high-risk strategy (by stipulation, cost or other factors mean we cannot implement both). For example, we might face a choice between providing a low dosage of statins to all those at slight risk of heart disease, or providing a higher dosage of statins to only those individuals with the highest serum cholesterol levels. Ex ante contractualism implies that in the relative version of the prevention paradox we ought to implement the high-risk rather than the population strategy. From the ex ante perspective, an individual in the highrisk group has a stronger claim to assistance than any individual in the population group, since those in the high-risk group have a greater chance of death from heart disease than those in the population group. As John notes, this normative prescription is consistent with the intuitions of many members of the public, and policy professionals.

J. Paul Kelleher ${ }^{40}$, writing in isolation of John, argues to the contrary, that in the types of cases characterised by the relative version of the prevention paradox, the fact that population strategies work by reducing many individual's small risk even further does 
not weaken the case for population strategies. If we can implement a population strategy or high-risk strategy, but not both, we ought to implement the population strategy. Kelleher's arguments would seem to support Rose's own apparent view that the population strategy is preferred over the high-risk strategy. My focus here though is not the correct normative account for relative version of the prevention paradox, but rather some difficulties that arise when ex ante contractualism is applied to the relative version.

$\mathrm{John}^{41}$ notes that there are some types of relative prevention paradox cases where ex ante contractualism seems to give the wrong normative prescription. These cases are where there is a large difference in the risks faced by the population and high-risk groups, as well as a large difference in the number of lives that might be saved. To use John's own numbers, suppose there are 100,000 people at a 0.5 risk of death and 100 million people at a 0.01 risk of death; if we implement the high-risk strategy we save the lives of 50,000 people but if we implement the population strategy we save the lives of 1 million people. Ex ante contractualism requires that we implement the high-risk strategy, and save 50,000 lives, since any given member of the high-risk group is at a much higher ex ante risk of death from heart attack than any given member from the population group. But this prescription may seem deeply counterintuitive, given that it entails the avoidable deaths of 1 million other individuals.

I suggest that the explanation for why ex ante contractualism gives the wrong answer in some instances of the relative version of the prevention paradox is that where a policy choice is genuinely competitive between different individuals, and we are 
forced to make inter-personal trade-offs, the ex post outcomes can have normative significance. It seems that what is driving the intuition that we ought to implement the population rather than the high-risk strategy in these cases is the sheer number of lives at stake. We ought to consider the ex post complaints of those who will actually die from heart disease, and not merely focus on the ex ante risks that individuals face. Addressing this point in detail is beyond the scope of this paper. But I suggest that the intra-personal comparisons are distinctive to the absolute version of the prevention paradox. These intra-personal comparisons privilege ex ante prospects over ex post outcomes in the absolute version of the prevention paradox. But applying the normative solution from the absolute version of the prevention paradox to the relative version gives a misleading steer, since the relative version of the prevention paradox involves inter-personal comparisons. ${ }^{42}$

\footnotetext{
${ }^{1}$ Other relevant public health problems could be the incidence of smoking, obesity, tooth decay, or deaths from air pollution.

${ }_{3}^{2}$ Alternatively, we might prescribe statins to a much wider group.

${ }^{3}$ Geoffrey Rose, 'Strategy of prevention: lessons from cardiovascular disease.', British Medical Journal, 282 (1981): 1847-1851. P.1849.

${ }^{4}$ Geoffrey Rose, Kay-Tee Khaw and Michael Marmot Rose's Strategy of Preventive Medicine. (New York: Oxford University Press 2008). P.48.

${ }^{5}$ Rose, 1981, op. cit.

${ }^{6}$ Stephen John, 'Risk, Contractualism, and Rose's "Prevention Paradox".', Social Theory and Practice, 40,1 (2014): 28-50.

${ }^{7}$ I assume throughout this paper that policy makers are aware of the preference - which all individuals share - for not implementing the population strategy.

${ }^{8}$ Obviously the clean distinction between absolute and relative versions of the prevention paradox is artificial. In many real-world cases, different individuals will respond differently to the same level of risk; some will want to implement the preventative strategy, and others will not. However, this abstraction is characteristic of the literature, and helps in addressing the normative points.

${ }^{9} \mathrm{I}$ do not address the correct resolution of the 'paradox', since the prevention paradox is not really a paradox in the true sense of the term.

${ }^{10}$ Rose, 2008, op. cit., p.48.

${ }^{11}$ Rose, 2008, op. cit., p.61.

${ }^{12}$ Rose, 1981, op. cit., p. 1851.

${ }^{13}$ Rose, 2008, op. cit., p.50.

${ }^{14}$ John 2011, op. cit. See also Stephen John, 'Why the Prevention Paradox is a paradox, and why we should solve it: A philosophical view.', Preventative Medicine, 53 (2011): 250-252.

${ }^{15}$ John, 2014, op. cit., p.32.
} 
${ }^{16}$ See John, 2014, op. cit., p.31.

${ }^{17}$ Rose suggested that population-based preventative health strategies can help those at high-risk, by shifting the entire distribution of risk in the wider population: the behavior of high-risk individuals may shift with the population norm. I address this issue later in the paper.

${ }^{18}$ By analogy, if these were 'trolley' cases, we are faced with a 'switch' type of trolley case, rather than a 'bridge' type trolley case. See Judith Jarvis Thomson 'The Trolley Problem.', Yale Law Journal 94 (1985): 1395-1415, and related literature.

${ }^{19}$ Michael Otsuka and Alex Voorhoeve, 'Why it matters that some are worse off than others.', Philosophy and Public Affairs, 37, 2, (2009): 172-199.

${ }^{20}$ Their paper, as a whole, presents arguments against prioritarianism. Prioritarianism, so they argue, cannot accommodate the intuition that maximising expected utility is permissible in cases of intrapersonal trade-offs. Note that on Otsuka and Voorhoeve's view the permissibility of maximising expected utility in intrapersonal trade-offs requires that we can consider persons in isolation from how others fare.

${ }^{21}$ Note that the same survey evidence suggests that people's intuitions shift when the costs and benefits of a treatment strategy fall on different people. Here, intuitions suggest that we should give precedence to those who are worst-off. For example, if there is a choice between funding treatment to entirely cure a slight impairment in one person, or a treatment to turn a very severe impairment into a less severe impairment in an entirely different person, then the latter treatment is to be preferred.

${ }^{22}$ Otsuka and Voorhoeve, 2009, op. cit., p.179.

${ }^{23}$ Suppose also, for the sake of argument, that the sorts of accommodations made available for people with genuine physical disabilities, such as stair lifts, are not suitable for individuals who just do not want to take exercise.

${ }^{24}$ John, 2014, op. cit.

${ }^{25}$ And if we consider all three sources of complaints via contractualism simpliciter (rather than exante- or ex-post contractualism), and we treat these complaints as arising from different individuals, then it seems, prima facie, as if we ought to implement the population-based preventative strategy since those who will die if we don't implement the strategy seem to have the strongest complaints.

${ }^{26}$ Otsuka and Voorhoeve, 2009, op. cit.

${ }^{27}$ This type of prudential argument is originally presented in Otsuka and Voorhoeve, 2009, op. cit., and expanded on in Michael Otuska, 'Prioritarianism and the Separateness of Persons.', Utilitas 24 (2012): 365-80.

${ }^{28}$ They also note that egalitarian concerns might be accounted for by the thought that inequality between persons is intrinsically bad. But, as they point out, this interpretation of egalitarianism is subject to Derek Parfit's 'leveling down' objection.

${ }^{29}$ Marc Fleurbaey and Alex Voorhoeve, 'Decide as You Would with Full Information! An Argument against et ante Pareto.', in Eyal, N, Hurst, S, Norheim, O, and Wikler, D, eds. Inequalities in Health: Concepts, Measures, and Ethics. (New York: Oxford University Press, 2014) pp. 115-128.

${ }^{30}$ This reason of autonomy is absent in the cases presented in Otsuka and Voorhoeve 2009, and this helps explain why Otuska and Voorhoeve's view is different from the one I advance in this paper. They state clearly that their arguments against prioritarianism and in favour of egalitarianism go through even when the individuals concerned are children, incapable of forming autonomous preferences, and where the person who has to decide what treatment to provide is not acting as agent of those facing impairment (e.g. the agent is not the doctor of an individual facing impairment). In the examples addressed by Otsuka and Voorhoeve, where prudential concerns are opposed by egalitarian concerns, and the issues of autonomy are irrelevant, they argue that the concern for ex post equality is decisive. While issue of autonomy might be a distraction for the analysis of Otsuka and Voorhoeve (and their critique of prioritarianism), autonomy is a 'feature' not a 'bug' of absolute versions of the prevention paradox. Relatedly, the arguments Marc Fleurbaey and Alex Voorhoeve advance against ex ante Pareto reasoning specifically assume that the agents affected by the policy decision are children. This is “...in order to eliminate the consideration that a morally-motivated stranger has reason to do what will maximize the expected utility of each out of respect for their autonomy. (One might argue that a respect for autonomy would require such expected utility-maximization if one assumed preferencebased measure of utility of the kind elaborated [in that paper].)" See Fleurbaey and Voorhoeve, 2014, op. cit., footnote 5 .

${ }^{31}$ It bears emphasis that in the absolute version of the prevention paradox there is - by stipulation - a consensus against implementing the population strategy. If some were in favour of implementing the population strategy, and some against, then inter-personal comparisons would be relevant. 
${ }^{32}$ Thomas Scanlon, 'Contractualism and Utilitarianism.' in Sen, A and Williams, B, eds. Utilitarianism and Beyond. (Cambridge: Cambridge University Press, 1982) pp.103-127.

${ }^{33}$ Frances Kamm, 'Should You Save This Child? Gibbard on Intuitions, Contractualism, and Strains of Commitment.', in Gibbard, A, ed. Reconciling Our Aims: In Search of Bases for Ethics, (Oxford: Oxford University Press, 2008) pp. 121-128. P.133.

${ }^{34}$ Fleurbaey and Voorhoeve, 2014, op. cit. Similar arguments are presented in Otsuka and Voorhoeve 2009, op. cit., and Otuska, 2012, op. cit.

${ }^{35}$ Johann Frick, 'Uncertainty and Justifiability to Each Person: Response to Fleurbaey and Voorhoeve.', in Eyal, N, Hurst, S, Norheim, O, and Wikler, D, eds. Inequalities in Health: Concepts, Measures, and Ethics. (New York: Oxford University Press, 2014) pp.130-146.

${ }^{36}$ See Rose, 2008, op. cit., and John, 2011, op. cit.

${ }^{37}$ Also excluded would be cases where the population strategy is intended to stop one individual imposing risks on others, such as a ban on cell phone use when driving.

${ }^{38}$ I thank an anonymous referee for suggesting this example.

${ }^{39}$ See Otsuka and Voorhoeve 2009, op. cit., p.179.

${ }^{40}$ J. Paul Kelleher, 'Prevention, Rescue and Tiny Risk.' Public Health Ethics, 6,3 (2014): 252-261.

${ }^{41}$ John, 2014, op. cit.

${ }^{42}$ I would like to thank Clare Chambers, Ben Ferguson, Stephen John, Marco Meyer, and Alex Voorhoeve for helpful discussions and comments. 